\title{
RESPONSABILIDAD DEL ESTADO Y CAMBIO CLIMÁTICO: EL CASO URGENDA CONTRA PAÍSES BAJOS*
}

\author{
NoEl Rodríguez GARCÍA \\ Universidad Autónoma de Madrid \\ noel.rodriguez@estudiante.uam.es
}

Recibido: 9 de mayo de 2016 / Aceptado: 19 de octubre de 2016

RESUMEN: En relación con el cambio climático, el sistema convencional de las Naciones Unidas no ha sido eficaz a la hora de fiscalizar las responsabilidades. En contraposición, la litigación ambiental se ha convertido en un instrumento altamente útil en este sentido, y en este ámbito el caso Urgenda contra Países Bajos introduce varias cuestiones novedosas. En primer lugar, es interesante la aplicación que se lleva a cabo del principio de objetivación de la tutela ambiental, con el que se desplaza totalmente la discusión fáctica en favor de la jurídica, remitiéndose a lo establecido a nivel científico y técnico. En segundo lugar, la existencia de un deber de cuidado del Estado frente al cambio climático es extraída del régimen neerlandés de responsabilidad civil extracontractual, en virtud del cual el Tribunal consideró responsable al Estado sin necesidad de una norma concreta. La aplicación de este deber de cuidado lleva implícitos dos juicios: uno acerca de la presencia de un deber genérico de cuidado y otro acerca de la diligencia observada en el cumplimiento de ese deber. El último de estos juicios surgido a la luz del principio de precaución - es especialmente importante por cuanto el primero depende de él y porque plantea ciertas tensiones en relación con la separación de poderes.

\footnotetext{
* Este estudio ha sido elaborado como Trabajo de Fin de Grado del Grado de Derecho de la Universidad Autónoma de Madrid y ha sido tutelado por Rosa María Fernández Egea, profesora contratada doctora de Derecho Internacional Público (UAM, Facultad de Derecho).
} 
RESUM: En relació amb el canvi climàtic, el sistema convencional de les Nacions Unides no ha estat eficaç a l'hora de fiscalitzar les responsabilitats. En contraposició, la litigació ambiental ha esdevingut un instrument altament útil en aquest sentit. En aquest àmbit, el cas Urgenda contra els Països Baixos introdueix diverses qüestions noves. En primer lloc, és interessant l'aplicació que es du a terme del principi d'objectivació de la tutela ambiental, amb el que es desplaça totalment la discussió fàctica en favor de la jurídica, tot remetent-se al que s'ha establert en el context científic i tècnic. En segon lloc, l'existència d'un deure de cura per part de l'Estat davant del canvi climàtic s'extrau del règim neerlandès de responsabilitat civil extracontractual, en virtut del qual el Tribunal ha considerat responsable a l'Estat sense necessitat d'una norma concreta. L'aplicació d'aquest deure de cura du implícits dos judicis: un en relació a la presència d'un deure genèric de cura, i un altre en relació a la diligència observada en l'acompliment d'aquest deure. El darrer d'aquests judicis — sorgit a la llum del principi de precaució- és especialment important, en la mesura que el primer depèn d'ell i perquè planteja certes tensions en relació amb la separació de poders.

ABSTRACT: Concerning climate change, the conventional system of the United Nations has not been effective in controlling the responsibilities. In contrast, environmental litigation has become a highly useful tool for this matter, and in this area the Urgenda $v$. Netherlands case introduces some ground-breaking issues. Firstly, the application here of the principle of objectivation of environmental protection is interesting, as it is used to shift the factual discussion towards a legal one. Secondly, the existence of a duty of care for climate change is found in the Dutch tort liability regime, under which the court considered the State accountable without needing a well-defined rule. The application of this duty of care comprises two judgements: one about the presence of a generic duty of care, and another about the standard of care followed in fulfilling that duty. The latter of those judgments - executed in the light of the precautionary principle - is particularly important, as the former depends upon it and as it creates certain strains in relation to the separation of powers. 
PALABRAS CLAVE: Cambio climático — Litigación ambiental — Responsabilidad estatal — Responsabilidad civil extracontractual.

PARAULES CLAU: Canvi climàtic — Litigació ambiental — Responsabilitat estatal - Responsabilitat civil extracontractual.

KEYWORDS: Climate change - Environmental litigation — State responsibility — Tort liability.

Sumario: I. Cambio climático, derecho internacional del medio ambiente y litigación ambiental. II. El caso Urgenda contra Países Bajos. 1. Contexto del caso. 2. Legitimación de Urgenda. 3. Hechos: el estado actual de la ciencia. 3.1. El principio de objetivación de la tutela medioambiental. 4. Fundamentos jurídicos: perspectiva general. 4.1. El principio de interpretación conforme. 5. El artículo 6:162 del Código Civil holandés. 5.1. La acción u omisión. A. La cuestión de la antijuridicidad. B. La existencia de una obligación legal. B.1. El artículo 21 de la Constitución de los Países Bajos. B.2. Derecho internacional y de la Unión Europea. C. El deber de cuidado. 5.2. El daño. A. Los artículos 2 y 8 del Convenio Europeo de Derechos Humanos. A.1. El medio ambiente como derecho humano. B. El principio de no causar daños transfronterizos. 5.3. El nexo causal. 5.4. La culpabilidad. A. La incidencia de los principios de objetivación, prevención y precaución. B. La aplicación del principio de precaución. El análisis costebeneficio. C. Los efectos políticos de la decisión y la separación de poderes. III. Conclusiones. IV. Bibliografía.

\section{CAMBIO CLIMÁtico, DERECHO INTERNACIONAL DEL MEDIO AMBIENTE Y LITIGACIÓN AMBIENTAL}

El cambio climático es sin duda uno de los problemas de mayor relevancia a nivel global, pues su radical deslocalización, su incierta determinación con el estado actual de la ciencia y su conexión con el crecimiento económico constituyen dificultades que convierten su solución en extremadamente compleja ${ }^{1}$.

El remedio convencional en el contex to de las Naciones Unidas a este problema ha pasado por la Convención Marco sobre el Cambio Climático de 1992 y el Protocolo de Kioto de 1997, el cual, a pesar de haber sentado las bases de un sistema estable de protección, se

\footnotetext{
${ }^{1}$ JUSTE RUIZ, J., "El régimen internacional para combatir el cambio climático en la encrucijada", Giles Carnero, R. (dir.), Cambio climático, energía y derecho internacional: perspectivas de futuro, Aranzadi, Navarra, 2012, pp. 37-49, pp. 37-40.
} 
muestra como un "instrumento con un objetivo poco ambicioso y claramente insuficiente"2.

Tras la Conferencia de las Partes en Durban de 2011 (COP 17), resultaba clara la necesidad de un sistema integral que pusiese freno al fraccionamiento causado por la rigidez del sistema de Kioto $^{3}$, no solventada por los mecanismos de cumplimiento flexible. Por este motivo, la característica principal de la Plataforma de Durban es la voluntad subyacente de iniciar un nuevo proceso de negociación orientado a la consecución de un nuevo acuerdo comprensivo sobre cambio climático ${ }^{4}$. Con dicha voluntad se llegó a la Conferencia de París (COP 21), celebrada entre los días 30 de noviembre y 11 de diciembre de 2015. Del acuerdo allí logrado, el primer aspecto que tenemos que resaltar es la no obligatoriedad del cumplimiento de los compromisos de reducción de emisiones, dejándose además en manos de los Estados su fijación ${ }^{5}$. Ello supone, por tanto, que sigan sin contemplarse en el ámbito de la Convención Marco mecanismos para fiscalizar la actividad de los países y eventualmente sancionar a aquellos que no cumplan sus compromisos ${ }^{6}$.

En segundo lugar, destaca el sistema de revisión cada cinco años establecido en su artículo 14, que dispone que los Estados deberán determinar periódicamente el grado de cumplimiento de los objetivos con el fin de ir aumentando la ambición de estos ${ }^{7}$. Las partes consideran necesario actualizar este régimen cada poco tiempo, pues tanto las contribuciones presentadas por las partes como el objetivo global plantean dos dificultades principales. En primer lugar, en su determinación interviene un interés con una tremenda importancia como es el del ya señalado crecimiento económico, que

\footnotetext{
${ }^{2}$ GILES CARNERO, R., "El Protocolo de Kioto como modelo de gestión ambiental global”, Remiro Brotóns, A. y Fernández Egea, R.M. (dirs.), El cambio climático en el Derecho Internacional y Comunitario, Fundación BBVA, Bilbao, 2009, pp. 27-60, p. 58.

3 JUSTE RUIZ, “El régimen...”, cit., pp. 47-49.

${ }^{4}$ PASPATI, E., "The output of the Durban climate change negotiations: a first critical approach", Mepielan eBulletin, 22 de febrero de 2012. Disponible en: http://www.mepielanebulletin.gr/default.aspx?pid=18\&CategoryId=8\&ArticleId=93\&Article=The-Output-of-the-DurbanClimate-Change-Negotiations-A-First-Critical-Approach.

${ }^{5}$ BERMEJO, R. y EGUILlOR, L., “COP 21 ¿Éxito o fracaso?”, Centro de Documentación Hegoa, Boletín de recursos de información, núm. 45, diciembre de 2015, pp. 1-8.

${ }^{6}$ BORRÁS PENTINAT, S., "Los litigios climáticos: Entre la tutela climática y la fiscalización de las responsabilidades por daños climáticos”, Giles Carnero, R. (dir.), Cambio climático, energía y Derecho Internacional: perspectivas de futuro, Aranzadi, Navarra, 2012, pp. 91-104, pp. 91-92.

${ }^{7}$ Acuerdo de París, 21. ${ }^{\text {er }}$ período de sesiones de la Conferencia de las Partes, Convención Marco sobre el Cambio Climático de las Naciones Unidas, celebrado en París el 12 de diciembre de 2015.
} 
constituye un óbice a objetivos o contribuciones de reducción más sustanciales. Por ello, ante la dificultad de alcanzar compromisos suficientes desde el primer momento, se prefiere ir aumentándolos progresivamente. En segundo lugar, no se quiere volver a caer en la rigidez del régimen de Kioto. Siendo el cambio climático, como ya hemos señalado, un problema cuyos efectos son difíciles de determinar, las soluciones establecidas a priori corren el riesgo de quedarse obsoletas o mostrarse inadecuadas rápidamente dado que es imposible asegurar su efectividad ex ante y es fácil que el sistema se muestre agarrotado. Por ello, se trata de facilitar su adaptabilidad para que no sea necesario recurrir a instancias externas —como nuevos protocolos paralelos o determinadas instancias políticas cualificadas $(\mathrm{G} 8, \mathrm{G} 20 \text {, etc. })^{8}$ -

En definitiva, vemos que el régimen convencional lleva aparejados algunos problemas. En primer lugar, las obligaciones contraídas son poco ambiciosas pues tanto las contribuciones estatales como el objetivo convencional global están sometidos a tensiones políticas en su fijación que afectan de manera ostensible a su alcance, por lo que lo normal es que se ajusten tan solo a los mínimos establecidos por la ciencia, en el mejor de los $\operatorname{casos}^{9}$. En segundo lugar, aun estableciéndose un sistema ambicioso, ello no implicaría que fuera eficaz, dado que esto depende en última instancia de la voluntad de las partes de utilizar los mecanismos de cumplimiento. Muestra de ello es la pérdida de protagonismo de los mecanismos de control de carácter coercitivo de Kioto, al haber dependido el respeto de las partes al Protocolo no de estos mecanismos, sino de la garantía de no ser excluidas del sistema a cambio de dicho respeto ${ }^{10}$. Cualquier otro mecanismo convencional podría, por tanto, devenir ineficaz por desuetudo independientemente de haber sido establecido por los mismos Estados cuando estos no recurriesen a él. En último lugar, incluso fijándose un sistema ambicioso y vinculante, el carácter indeterminado del cambio climático dificulta que las obligaciones mencionadas mantengan su condición de suficiencia con el paso del tiempo, lo que hace necesario un sistema que pueda adaptarse

\footnotetext{
${ }^{8}$ JUSTE RUIZ, “El régimen...”, cit., pp. 48-49.

${ }^{9}$ PURNHAGEN, K., "Towards a regime of emission litigation based on science", Wageningen Working Papers in Law and Governance, Law and Governance Group, 2015/10, p. 2.

${ }^{10}$ PEYRÓ LLOPIS, A., "Los mecanismos de control del cumplimiento de las obligaciones previstas en el Protocolo de Kioto", Remiro Brotóns, A. y Fernández Egea, R.M. (dirs.), El cambio climático en el Derecho Internacional y Comunitario, Fundación BBVA, Bilbao, 2009, pp. 61-85, pp. 84-85.
} 
eficazmente a las nuevas exigencias que se le planteen ${ }^{11}$, en línea con el carácter flexible del derecho internacional del medio ambiente (en adelante, DIMA) ${ }^{12}$.

Estos tres elementos ganan relevancia en referencia a la exigencia de responsabilidad por daños climáticos. No solo la Convención Marco carece de mecanismos para sancionar el incumplimiento de sus compromisos, sino que a la vista de las características del sistema — escaso alcance, rigidez y no obligatoriedad - no parece que vaya a ser dotado de instrumentos en este sentido en el corto o medio plazo. En efecto, es fuera de los instrumentos de Naciones Unidas donde tenemos que buscar un mecanismo flexible que pueda identificar obligaciones de los Estados respecto al cambio climático y que no esté sujeto a intereses extrajurídicos que pudiesen rebajar el grado en que los países responden por aquellas actuaciones de las cuales son responsables.

En estas circunstancias, asume un papel clave la litigación ambiental, tanto estatal como internacional, a la que ha recurrido la sociedad civil para llenar el vacío de la fiscalización de los daños climáticos ${ }^{13}$, en un intento por reforzar los estándares de protección conocido como regulation-through-litigation-approach. Aunque esta vía ha fracasado en múltiples ocasiones por la reticencia de los tribunales a reconocer la existencia de derechos subjetivos frente a los Estados, va ganando progresivamente peso en el contexto del DIMA $^{14}$.

El objeto del presente trabajo es precisamente analizar una de las últimas resoluciones de un litigio de este tipo, en concreto el caso Urgenda contra Países Bajos. Como veremos, se trata de la decisión que más lejos ha ido a la hora de establecer la responsabilidad estatal respecto al fenómeno del cambio climático. Así, se tratará de poner este caso en perspectiva respecto de otros relevantes, con el objetivo de identificar sus elementos novedosos, y se analizarán los motivos en los que el Tribunal basa su decisión, relacionándolos con principios asentados a nivel internacional, con el fin de aventurar si

\footnotetext{
${ }^{11}$ Véase ANTUNES, T., "The 'normative adaptation' to climate-related events", Giles Carnero, R. (dir.), Cambio climático, energía y Derecho Internacional, perspectivas de futuro, Aranzadi, Navarra, 2012, pp. 65-78.

12 JUSTE RUIZ, “El régimen...", cit., p. 48.

${ }^{13}$ LIN, J.S.W., "The first successful climate negligence case: A comment on Urgenda Foundation v. The State of the Netherlands", Climate Law (Brill Publishing), 2015, v. 5, núm. 1, pp. 65-81, pp. 65-67.

${ }^{14}$ PURNHAGEN, “Towards a regime...”, cit., p. 2.
} 
estamos ante una decisión aislada o si la ratio que la fundamenta es replicable en otros ámbitos.

\section{EL CASO URGENDA CONTRA PAÍSES BAJOS}

\section{Contexto del caso}

El 20 de noviembre de 2013, la organización Urgenda, actuando en representación de 886 particulares y propia, demandó al Ministerio de Infraestructuras y Medio Ambiente (Ministerie van Infrastructuur en Milieu). En el núcleo de sus pretensiones estaba que el Tribunal ordenase al ejecutivo holandés que actuara para que en 2020 se reduzca la cantidad de emisiones de $\mathrm{CO}_{2}$ respecto a 1990 en un $40 \%$ o, al menos, en un $25^{15}$.

En su sentencia de 24 de junio de 2015, el Tribunal del Distrito de La Haya decidió atender la petición referida y, a pesar de no existir un mandato legal preciso, declaró al Gobierno de los Países Bajos responsable de asegurar que las emisiones de $\mathrm{CO}_{2}$ decrezcan en la medida indicada por Urgenda, y consecuentemente lo conminó a actuar para limitar el volumen de $\operatorname{estas}^{16}$. De esta manera, los Países Bajos retornan a una posición clave en cuanto a protección medioambiental en Europa en la que se habían situado desde la década de 1980, pero de la que se habían alejado en la última década ${ }^{17}$.

\section{Legitimación de Urgenda}

Como cuestión preliminar al estudio del razonamiento jurídico de la sentencia, debemos analizar la existencia o no de legitimación, puesto que es clave a la hora de determinar la efectividad de la litigación ambiental como mecanismo de protección.

En el caso no se discute que la parte demandante no actúe legítimamente al representar los intereses de la actual generación de ciudadanos holandeses en relación con las emisiones producidas desde territorio de los Países Bajos puesto que, según el Estado, estos son los intereses que Urgenda defiende de acuerdo con sus estatutos. No obstante,

\footnotetext{
${ }^{15}$ Véase Urgenda Foundation. Summons. 25 de junio de 2014. Disponible en: http://www.urgenda.nl/en/climate-case/.

${ }^{16}$ Países Bajos, Tribunal del Distrito de La Haya (Sala de lo Mercantil). Caso Urgenda contra Países Bajos. Sentencia de 24 de junio de 2015 (ECLI:NL:RBDHA:2015:7196). Párr. 5.1.

${ }^{17}$ VAN ZEBEN, J., "Establishing a governmental duty of care for climate change mitigation: Will Urgenda turn the tide?”, Transnational Environmental Law, 2015, núm. 4, pp. 339-357, pp. 339-342.
} 
sí argumenta que esta no está legitimada para actuar en interés de generaciones futuras fuera del territorio neerlandés — mientras que delega en el Tribunal la decisión sobre si lo está respecto de generaciones futuras dentro de dicho territorio- ${ }^{18}$, dado que sus pretensiones (antes indicadas) son reflejo de los mencionados intereses. En consecuencia, considera que no se cumple el requisito del artículo 305a (Libro 3) del Código Civil holandés, cuyo primer punto indica que un sujeto como la demandante solo puede actuar en defensa de los intereses o derechos cuya protección tenga como objeto ${ }^{19}$.

Sin embargo, el Tribunal desmonta este razonamiento sobre la base del artículo 2 de los estatutos de Urgenda, que establece como objeto de la actividad de esta "la consecución de una sociedad más sostenible", a lo que añade "comenzando por los Países Bajos”. Esto es interpretado por el órgano judicial como una prioridad, no como una limitación territorial, tal y como la consideraba la parte demandada ${ }^{20}$. Por tanto, viene a establecer que la promoción de la sostenibilidad en la sociedad es un objetivo intrínsecamente intergeneracional y transfronterizo ${ }^{21}$.

Esto constituye una interpretación bastante amplia de la legitimación, pues permitiría a casi cualquier ONG esgrimir pretensiones similares, con proyección internacional, siempre que no circunscriban su actuación a un determinado territorio. Lo cual resulta relevante pues, como veremos, en caso de daños medioambientales no es fácil individualizar la responsabilidad, y cualquiera que trate de exigirla estará actuando, en general, en defensa de un interés transfronterizo, por lo que una interpretación más restrictiva eliminaría la posibilidad de litigar en un gran número de $\operatorname{casos}^{22}$.

\section{Hechos: el estado actual de la ciencia}

En su sentencia, el Tribunal considera como antecedentes de hecho diversas cuestiones relativas al derecho medioambiental y al estado actual de la ciencia. Aunque ya se ha descrito en líneas generales el contexto actual del DIMA, cabe añadir algunas precisiones relativas a la reducción de emisiones de gases de efecto invernadero. Según el Cuarto

\footnotetext{
${ }^{18}$ Urgenda..., cit., párr. 4.5.

${ }^{19}$ Ibidem.

${ }^{20}$ Idem, párr. 4.7.

${ }^{21}$ VAN ZEBEN, “Establishing a governmental...”, cit., pp. 345-346.

22 ROY, S., "Situating Urgenda versus the Netherlands within comparative climate change litigation", Journal of Energy \& Natural Resources Law, v. 34, 2016, pp. 7-8.
} 
Informe de Evaluación del Grupo Intergubernamental de Expertos sobre el Cambio Climático (IPCC), la única manera de prevenir un cambio climático irreversible y peligroso para el medio y el ser humano es evitar un aumento de la temperatura global superior a $2{ }^{\circ} \mathrm{C}$ respecto a niveles preindustriales (con un nivel de concentración de gases de efecto invernadero de 450 ppm $)^{23}$. Así se estableció en la Conferencia de las Partes de la Convención Marco de 2010 (Acuerdos de Cancún) ${ }^{24}$, y así se ha mantenido en la Conferencia de París ${ }^{25}$, y de igual manera se confirmó en el Quinto Informe de Evaluación ${ }^{26}$. En este último se indicó que, con tal de lograr los niveles indicados, es necesario que los países del anexo I de la Convención Marco, entre los que se encuentran Holanda y el resto de la UE, reduzcan sus emisiones de manera que para 2020 sean inferiores a los niveles de 1990 de un $20 \%$ a un $40 \%$, dependiendo del tipo de Estado ${ }^{27}$. En estas circunstancias, el Consejo Europeo consideró adecuado que la UE se comprometiese a una reducción del $20 \%$, ampliable a un $30 \%$ en caso de que los otros países del anexo I garantizasen una reducción de la misma magnitud ${ }^{28}$. Dado que esto no ha sucedido, los Países Bajos, en línea con la UE y a pesar de que en un primer momento sí respaldaron una reducción del 30\%, han fijado finalmente su objetivo en un $20 \%$, lo cual es insuficiente a la vista de lo expuesto $y$, sobre todo, a la vista de que las expectativas reales de reducción se estiman en unos niveles que oscilan entre un $14 \%$ y un $17 \%{ }^{29}$.

Sobre la base de estas circunstancias alegadas por la demandante y aceptadas por el Tribunal como base fáctica, la primera pretendía que se obligase al Estado a cumplir los objetivos de reducción marcados por el IPCC, establecidos en función de criterios científicos. Dejando a un lado la existencia o no de una obligación jurídica a ello, cuestión que debemos posponer por ahora, cabe señalar que las pretensiones de la actora son reflejo de lo que podemos denominar como principio de objetivación de la tutela medioambiental.

\footnotetext{
${ }^{23}$ Urgenda..., cit., párr. 4.13, 4.14, 4.20 y 4.22.

${ }^{24}$ Idem, párr. 4.14.

25 Acuerdo de París, cit.

${ }^{26}$ Urgenda..., cit., párr. 4.27.

${ }^{27}$ Idem, párr. 4.24.

${ }^{28}$ Idem, párr. 4.25.

${ }^{29}$ Idem, párr. 4.26.
} 


\subsection{El principio de objetivación de la tutela medioambiental}

Este principio supone que la toma de decisiones en materia ambiental, tanto legal como reglamentariamente, debe ir acompañada de una base fáctica sólida en forma de estudios técnicos y científicos que justifiquen su necesidad. Nace de los principios de seguridad jurídica e interdicción de la arbitrariedad de los poderes públicos, configurándose como una concreción del deber de motivación que tiene la Administración, garantía frente a la discrecionalidad Estado ${ }^{30}$.

No obstante, este principio no solo consta de esta dimensión negativa, limitadora de la discrecionalidad del Estado (por cuanto implica que este se abstenga de determinadas actuaciones cuando no pueda justificarlas adecuadamente), sino también de una positiva, pues, tal y como lo entiende parte de la doctrina, se configura como un mandato a los poderes públicos para que establezcan los niveles de protección que resulten idóneos conforme a la ciencia. Así, en el caso Dieter Janecek contra Estado Libre de Baviera, el Tribunal de Justicia de la Unión Europea, en respuesta a una cuestión prejudicial planteada por el Tribunal Constitucional Federal Alemán —en relación con la aplicación del artículo 7.3 de la Directiva 96/62/CE, sobre evaluación y gestión de la calidad del aire ambiente_-, afirmó que "los Estados miembros [tienen] la obligación clara de elaborar planes de acción cuando exista riesgo tanto de superar los valores límite como de sobrepasar los umbrales de alerta" ${ }^{31}$, siendo estos valores establecidos conforme a criterios técnicos.

Obligaciones de este tipo subsisten en la normativa ambiental en vigor, como en la Directiva 2008/50/CE, relativa a la calidad del aire ambiente y a una atmósfera más limpia en Europa, que llama a los Estados miembros a "adoptar medidas para respetar los valores límite y los niveles críticos"32. También fuera de un contexto europeo es posible encontrar manifestaciones de este tipo, como en el artículo 11 la Carta Mundial de la Naturaleza,

\footnotetext{
${ }^{30}$ PEÑA CHACÓN, M., "Los principios de objetivación de la tutela a ambiental e irreductibilidad de espacios sometidos a régimen especial de protección y su relación con la prohibición de retroceso", Medio Ambiente y Derecho: Revista electrónica de derecho ambiental, núm. 25, diciembre de 2013, pp. $2-4$.

${ }^{31}$ Tribunal de Justicia de la Unión Europea. Caso Janecek contra Freistaat Bayern (C- 237/07, ECLI:EU:C:2008:447). Sentencia de 25 de julio de 2008. Párr. 35.

${ }^{32}$ Directiva 2008/50/CE del Parlamento Europeo y del Consejo, de 21 de mayo de 2008, relativa a la calidad del aire ambiente y a una atmósfera más limpia en Europa, Diario Oficial de la Unión Europea, núm. L152, de 11 de junio de 2008, pp. 1-44, punto 9 de las consideraciones preliminares.
} 
que anima a reducir al máximo el peligro para el medio con el uso de las mejores técnicas disponibles ${ }^{33}$.

En definitiva, en todo lo expuesto encontramos un elemento común, esto es, el papel de la ciencia y de la técnica como directrices de la protección estatal. Por último, conviene no olvidar que la presencia aquí del principio de objetivación guarda relación con la configuración de la base fáctica del caso y no tanto con el fondo del asunto, es decir, con la existencia o no de una obligación jurídica del Estado. En otras palabras, es un hecho que las reducciones de emisiones son necesarias, y, en virtud del principio expuesto, la actuación del Estado debe estar informada por ese hecho, si bien ello no significa que jurídicamente esté obligado a actuar al respecto, al menos a priori.

\section{Fundamentos jurídicos: perspectiva general}

A partir de los hechos descritos, que no fueron discutidos por el Tribunal, Urgenda trató de demostrar que, por una parte, existe una obligación legal y concreta para el Estado de actuar para conseguir una reducción de las emisiones, basándose para ello en los artículos 21 de la Constitución de los Países Bajos y 2, 8 y 13 del Convenio Europeo de Derechos Humanos (punto 5 del escrito de demanda), además de en el derecho internacional y de la Unión Europea (punto 4, apartados 2 a 4); por otra, la demandante intentó probar que, en todo caso, el Estado debía ser declarado responsable por la vía de la responsabilidad civil extracontractual del artículo 6:162 del Código Civil holandés (puntos 4.5 y 6 de la demanda) ${ }^{34}$.

El Tribunal optó por seguir esta segunda vía, apoyando la aplicación del artículo 162 en las otras normas invocadas - pese a no concederles eficacia directa- por medio de la interpretación conforme. Esto constituye una diferencia clave respecto al caso Janecek, en el que la exigencia de que los poderes públicos actuasen, y además lo hiciesen adecuándose a parámetros técnicos, se extrajo de una norma concreta, mientras que aquí el Tribunal determinó que, a pesar de la inexistencia de una regla precisa, el Estado holandés debía actuar ${ }^{35}$.

\footnotetext{
${ }^{33}$ Carta Mundial de la Naturaleza, Resolución 37/7 de la Asamblea General de las Naciones Unidas, del 28 de octubre de 1982.

${ }^{34}$ Summons, cit.

35 PURNHAGEN, “Towards a regime...", cit.
} 


\subsection{El principio de interpretación conforme}

Este principio se basa en la presunción de que el Estado tiene la voluntad de cumplir sus compromisos internacionales, lo que implica que la aplicación del derecho nacional solo podrá ser completamente contraria a estos compromisos cuando no quepa otra apreciación posible ${ }^{36}$. Por tanto, los principios y las reglas sobre los que se realice la interpretación conforme no constituirán un soporte autónomo de la sentencia, sino que se deberán canalizar a través de una regla jurídica nacional ${ }^{37}$. Por este motivo, se habla de "efecto indirecto"38 o "efecto reflejo" 39 .

Este mecanismo tiene una importancia capital en la litigación ambiental pues permite incorporar determinados principios y normas del DIMA — cuando no se puedan aplicar directamente - a la aplicación del derecho nacional, lo que permite una interpretación amplia de este último y puede concretarse en un refuerzo de la protección medioambiental. Así ocurrió en este caso, en el que el Tribunal construyó una obligación para el Estado a partir del artículo 6:162 del Código Civil de los Países Bajos, apoyando su interpretación además en la Constitución holandesa y las convenciones internacionales ya mencionadas.

Además, el principio en cuestión dota de sentido al presente trabajo pues, sin este principio, identificar los fundamentos jurídico-internacionales de la sentencia objeto de estudio resultaría superfluo al no existir un principio que motive el que en otras decisiones se utilicen fundamentos similares. Sin embargo, al promulgar la interpretación conforme, resulta clara la importancia del caso Urgenda dado que este instrumento posibilita que se repitan soluciones que también integren derecho internacional, por lo que este caso puede constituir un precedente básico.

\footnotetext{
${ }^{36}$ Urgenda..., cit., párr. 4.43.

${ }^{37}$ BETLEM, G. y NOLLKAEMPER, A., "Giving effect to Public International Law and European Community Law before domestic courts. A comparative analysis of the practice of consistent interpretation", European Journal of International Law, 2003, vol. 14, núm. 3, pp. 569-589, p. 572.

${ }^{38}$ Ibidem.

${ }^{39}$ LIN, “The first successful...”, cit., p. 74.
} 


\section{El artículo 6:162 del Código Civil holandés}

La interpretación del artículo 162 es el núcleo del razonamiento lógico-jurídico del Tribunal en el caso Urgenda, y puesto que los otros motivos solo son tenidos en cuenta en apoyo de dicha interpretación, no resulta pertinente separar el estudio de estos últimos respecto del análisis del primero. Lo que recoge este artículo es el instituto de la responsabilidad aquiliana, estableciendo en su apartado primero que "una persona que cometa un ilícito contra otra persona, que pueda atribuírsele, debe reparar el daño que esta otra persona ha sufrido en consecuencia" 40 .

Así, la mejor manera de entender el veredicto es analizar por separado los elementos que deben concurrir para que exista responsabilidad frente a los particulares, pues el objeto de la sentencia no es pronunciarse acerca de la responsabilidad internacional. De este modo se puede identificar la manera en que estos elementos o requisitos se relacionan individualmente con cada uno de los demás motivos, que son la existencia de una acción u omisión, la producción de un daño, la presencia de un nexo causal entre los anteriores y la concurrencia de culpabilidad, en forma de dolo o negligencia ${ }^{41}$.

\subsection{La acción u omisión}

A. La cuestión de la antijuridicidad

El primer presupuesto para la existencia de responsabilidad, tanto en el derecho holandés como en los sistemas comparados, es la ejecución de una acción o de una omisión ${ }^{42}$. No obstante, no todos los ordenamientos coinciden acerca de la necesidad de que dicha conducta sea contraria a derecho.

El artículo 162 del Código Civil holandés, en concreto, menciona la comisión de un ilícito (onrechtmatige daad), de manera similar a lo establecido en el Reino Unido o Alemania ${ }^{43}$. En estos sistemas, por tanto, no genera responsabilidad cualquier conducta que produzca un daño —como, en principio, sucede en Francia, España o Italia—, sino que para ello es

\footnotetext{
${ }^{40}$ Países Bajos. Código Civil de 21 de marzo de 1804. Boletín Oficial del Reino de los Países Bajos (Staatsblad van het Koninkrijk der Nederlanden), núm. 30, de 3 de septiembre de 1807. Una traducción al inglés se puede encontrar en: http://www.dutchcivillaw.com/civilcodegeneral.htm.

${ }^{41}$ VAN DAM, C., European Tort Law, 1. ${ }^{a}$ ed., Oxford University Press Inc., Nueva York, 2007, pp. 11 13.

${ }^{42}$ Ibidem.

${ }^{43}$ Código Civil de los Países Bajos, cit.
} 
necesario además que dicha conducta tenga la consideración de antijurídica. Se entiende como tal cualquier acción u omisión que viole un deber, cuya fuente puede ser tanto legal como consuetudinaria. En este sentido se pronuncia el legislador neerlandés en la definición de ilícito que ofrece en el apartado segundo del propio artículo 162.

La razón por la que conviene resaltar la disparidad entre ordenamientos es la gran diferencia que supone la prueba de la antijuridicidad en el caso Urgenda en comparación con casos anteriores. Cabría preguntarse, por tanto, si esta cuestión habría tenido tanta relevancia en un sistema que no exigiese la violación de un deber. Sin embargo, esta cuestión pierde importancia si nos fijamos en que la conducta enjuiciada en el caso es de tipo omisivo; dado que solo pueden dar lugar a responsabilidad aquellas omisiones cometidas cuando se tenga la obligación de actuar, toda omisión por la que se deba responder llevará implícita la calificación de antijurídica, tanto en aquellos ordenamientos que predican la ilicitud de la conducta como en los que no lo hacen ${ }^{44}$.

Por tanto, el paso lógico es analizar ahora los motivos con los que Urgenda alegó que existía una obligación legal de actuar.

\section{B. La existencia de una obligación legal}

B.1. El artículo 21 de la Constitución de los Países Bajos

Urgenda extrajo el primer precepto alegado en este sentido de la Constitución de los Países Bajos, cuyo artículo 21 recoge el mandato a los poderes públicos de velar "por la habitabilidad del país y por la protección y el mejoramiento del medio ambiente" 45 . El Tribunal interpretó que, aunque esta disposición no gozaba de la certeza suficiente como para determinar el modo concreto en que se debe cumplir su mandato, sí que se podía deducir un deber de cuidado genérico ${ }^{46}$.

No obstante, este modo de cumplimiento no otorga una discrecionalidad absoluta al Estado, pues debe ser observado con una determinada diligencia, lo cual enjuició el Tribunal al decidir sobre el fondo de la cuestión. En consecuencia, la Corte no entra a

\footnotetext{
${ }^{44}$ Sobre este tema, véase VAN DAM, European..., cit., pp. 251-254.

${ }^{45}$ Países Bajos. Constitución del Reino de los Países Bajos, publicada el 29 de agosto de 2008 por el Ministro del Interior, Relaciones del Reino y Asuntos Constitucionales.

${ }^{46}$ Urgenda..., cit., párr. 4.36.
} 
valorar si se ha vulnerado el artículo 21, pero subraya la relevancia de la discrecionalidad de los poderes públicos, cuyos límites serán enjuiciados en el resto del veredicto ${ }^{47}$.

\section{B.2. Derecho internacional y de la Unión Europea}

Ya se ha expuesto que el soporte real de la demanda está constituido por una serie de instrumentos jurídico-internacionales (Convención Marco, COP, IPCC) que informan acerca de los niveles mínimos de reducción de emisiones. Además de esta función de prueba fáctica, Urgenda pretendía encontrar en dichos instrumentos (y en el principio de responsabilidad por daños transfronterizos) una fuente de obligaciones respecto a los nacionales de los Estados que los suscribiesen ${ }^{48}$. Cabe recordar que, a este respecto, el carácter self-executing de una norma internacional depende principalmente de su precisión e incondicionalidad (además, por supuesto, de la voluntad de los sujetos obligados internacionalmente), lo cual aparece recogido — recuerda el Tribunal— en el artículo 93 de la Constitución de los Países Bajos, que otorga efícacia a "las estipulaciones de tratados y de acuerdos de organizaciones internacionales de derecho público que por su contenido puedan obligar a toda persona". Este precepto, según entiende la jurisprudencia del Tribunal Supremo neerlandés ${ }^{49}$, subordina la eficacia directa a dos condiciones: por una parte, que en la ejecución de la norma se vean implicados intereses directos de los particulares y, por otra, que el nivel de concreción sea tal que permita su aplicación directa. Sobre la base de estos criterios, se rechaza la posibilidad de que de las normas mencionadas se derive responsabilidad directa frente a Urgenda (o cualquier particular) debido a que no prescriben actuaciones lo suficientemente precisas, de forma que solo obligan a los Países Bajos frente a otros Estados ${ }^{50}$.

El Tribunal extrapola el mismo argumento a la aplicación directa de los artículos 11 y 191 a 193 TFUE, que establecen la defensa del medio ambiente como principio rector de

\footnotetext{
${ }^{47}$ LIN, “The first successful...", cit., p. 72.

${ }^{48}$ Urgenda..., cit., párr. 4.39 y 4.42.

${ }^{49}$ Países Bajos, Tribunal Supremo. Caso Spoorwegstaking. Sentencia de 30 de mayo de 1986 (ECLI:NL:HR:1986:AC9402); Países Bajos, Tribunal Supremo. Sentencia de 18 de abril de 1995 (ECLI:NL:HR:1995:AD4656).

${ }^{50}$ Ello se deduce de la sentencia del Tribunal Supremo citada en el caso Urgenda (párrafo 4.42.), en la que se deniega la invocación directa por particulares del artículo 2.4. de la Carta de las Naciones Unidas (prohibición del uso de la fuerza contra la integridad territorial o la independencia de otro Estado): Países Bajos, Tribunal Supremo (Sala de lo Civil). Caso Vrede y otros contra Países Bajos. Sentencia de 6 de febrero de 2004 (ECLI:NL:HR:2004:AN8071). Párr. 3.4.
} 
la política comunitaria ${ }^{51}$, y la Directiva 2003/87/CE, que recoge el régimen de comercio de derechos de emisión en la Unión Europea ${ }^{52}$. Cabe recordar que el efecto directo de los tratados en el ámbito de la Unión se subordina también a la precisión e incondicionalidad de los preceptos que se pretenda invocar, tal y como establece la jurisprudencia del Tribunal de Justicia ${ }^{53}$. En relación con las directivas, son precisas además la expiración del plazo de transposición y la deficiencia o ausencia de la adaptación ${ }^{54}$. En todo caso, en el caso Urgenda la Corte no aprecia ninguna diferencia respecto a lo comentado para las normas internacionales y considera que no se dan los requisitos para aplicar directamente ni las unas ni las otras, a pesar de que puedan "tener un impacto a través de las disposiciones abiertas del derecho nacional" ${ }^{\prime 5}$, lo que en el caso se traduce en su toma en consideración para interpretar los preceptos finalmente aplicados.

\section{El deber de cuidado}

Una vez expuesto el razonamiento del órgano judicial para negar la existencia de una norma directamente aplicable, toca analizar la lógica que sigue para interpretar que existe una obligación acorde al artículo 6:162 CC. Alternativamente a la ley, este artículo menciona como posible fuente de esta obligación la "ley no escrita" (ongeschreven recht), que se determina en función de la existencia de una "conducta socialmente exigible" (maatschappelijk verkeer betaamt) al causante del daño ${ }^{56}$.

A su vez, para establecer la presencia o no de esta conducta o pauta de comportamiento, la jurisprudencia holandesa (y el Tribunal del caso) recurre a la conocida como doctrina

\footnotetext{
${ }^{51}$ Tratado de Funcionamiento de la Unión Europea, entre S.M. el Rey de los Belgas, el Presidente de la República Federal de Alemania, el Presidente de la República Francesa [....], hecho en Roma el 25 de marzo de 1957. Diario Oficial de la Unión Europea, núm. 83, de 30 de marzo de 2010, pp. 47-199.

52 Directiva 2003/87/CE del Parlamento Europeo y del Consejo, de 13 de octubre de 2003, por la que se establece un régimen para el comercio de derechos de emisión de gases de efecto invernadero en la Comunidad y por la que se modifica la Directiva 96/61/CE del Consejo, Diario Oficial de la Unión Europea, núm. L275, de 25 de octubre de 2003, p. 32.

${ }^{53}$ Así se establece, por ejemplo, en: Tribunal de Justicia de la Unión Europea. Caso Van Gend en Loos (C-26/62, ECLI:EU:C:1963:1), Sentencia de 5 de febrero de 1963; caso Lütticke (C-57/65, ECLI:EU:C:1966:34), Sentencia de 16 de junio de 1966; caso Salgoil (C-13/68, ECLI:EU:C:1968:54), Sentencia de 19 de diciembre de 1968.

${ }^{54}$ Tribunal de Justicia de la Unión Europea. Caso Ratti (C-148/78, ECLI:EU:C:1979:110), Sentencia de 5 de abril de 1979; caso Becker (C-8/81, ECLI:EU:C:1982:7), Sentencia de 19 de enero de 1982.

${ }^{55}$ Urgenda, cit., párr. 4.44.

${ }^{56}$ Código Civil de los Países Bajos, cit.
} 
Kelderluik $^{57}$, que ofrece una serie de criterios al juez a la hora de decidir en esta materia ${ }^{58}$. Dichos criterios se basan en general en la posibilidad de que la conducta produzca un daño y en la magnitud de este, de manera que, cuanto más factible y potencialmente gravoso sea el perjuicio que se puede causar, más estricto será el deber de cuidado ${ }^{59}$. En la sentencia se identifican en concreto seis pautas: la naturaleza del daño, su previsibilidad, la probabilidad de que suceda, la naturaleza de los actos del Estado, la onerosidad de las medidas requeridas y la discrecionalidad estatal ${ }^{60}$.

En este punto es necesario trazar una distinción clara, al menos a nivel conceptual, entre deber de cuidado stricto sensu (duty of care) y estándar o nivel de diligencia (standard of care $)^{61}$. El primero de ellos se refiere a la obligación de actuar cuya existencia (e infracción) es necesaria para que una conducta omisiva sea relevante a efectos de responsabilidad. Este duty of care también es necesario respecto de las conductas activas en aquellos sistemas en los que se predica la antijuridicidad de estas. El standard of care, por su parte, está relacionado con el juicio de culpabilidad de la conducta, por lo que se relaciona con la reprochabilidad de esta, que dependerá del nivel de diligencia observado. De esta manera, el primero aparece como un deber de actuar o de abstenerse de hacerlo que admite cierta discrecionalidad en su realización, siempre que se cumplan los mínimos marcados por el segundo ${ }^{62}$. El ordenamiento jurídico donde más se ha tratado de remarcar esta distinción es el alemán, donde existe una extensa literatura acerca de la distinción entre ambos conceptos, la cual es defendida por la mayor parte de la doctrina ${ }^{63}$.

En la práctica, sin embargo, no es fácil establecer una línea clara entre ellos. En casos como el presente, la determinación de un deber en abstracto difícilmente se puede separar del pronunciamiento sobre su cumplimiento o no ${ }^{64}$, lo que ha sido utilizado como

\footnotetext{
${ }^{57}$ Países Bajos, Tribunal Supremo (Sala de lo Civil). Caso Kelderluik. Sentencia de 5 de noviembre de 1965 (ECLI:NL:HR:1965:AB7079). Una versión en holandés se puede encontrar aquí: http://www.juridischeuitspraken.nl/

${ }^{58}$ ROY, "Situating Urgenda...", cit., p. 27.

${ }^{59}$ Véase VAN MAANEN, G., TOWNEND, D. y TEFFERA, A., "The dutch 'Cellar Hatch' judgment as a landmark case for tort law in Europe: a brief comparison with English, French and German law with a Law and Economics flavour", European Review of Private Law, 2008, v. 16, issue 5, pp. 871-889.

${ }^{60}$ Urgenda, cit., párr. 4.63.

${ }^{61}$ El uso de los términos ingleses obedece a una razón metodológica dado que son los que de manera más clara enfatizan la distinción entre ambos conceptos.

${ }^{62}$ Urgenda, cit., párr. 4.53.

${ }^{63}$ VAN DAM, European..., cit., pp. 67-69.

${ }^{64}$ Idem, pp. 68-69.
} 
argumento para defender aquellos sistemas basados en la culpabilidad. En el caso Urgenda, de hecho, la Corte no distingue entre ambas cuestiones y las resuelve sobre la base de la doctrina Kelderluik.

En todo caso, esta distinción tiene gran relevancia, pues gracias a ella se pueden dividir los problemas jurídicos que el supuesto del caso Urgenda plantea. Por una parte, encontramos la problemática ausencia de una norma concreta que obligue a la adopción de medidas de reducción, que está relacionada con el duty of care, mientras que, por otra, resulta importante analizar la competencia del Tribunal para tomar decisiones con consecuencias políticas, lo cual entra dentro de la interpretación del standard of care por cuanto conlleva enjuiciar la discrecionalidad del Estado ${ }^{65}$.

Reservando la segunda cuestión para el apartado que le corresponde — la culpabilidad— , resulta necesario hacer una puntualización sobre la primera. El razonamiento del Tribunal es que las normas constitucionales, comunitarias e internacionales alegadas por Urgenda, si bien "imponen un deber de cuidado", también es cierto que "no aporta[n] certeza sobre la manera en que este deber de cuidado debería ser ejecutado"66, y que, por tanto, es necesario concretar ese deber con tal de fijar el marco en el que se mueva el estándar de diligencia ${ }^{67}$. En consecuencia, el Tribunal da tres "pasos": rechaza la eficacia directa, establece un deber de cuidado genérico y se pronuncia sobre su cumplimiento a través de la interpretación de la discrecionalidad del Gobierno. Así, es posible interpretar el segundo como redundante, pues se rechaza la aplicación directa de un deber genérico para deducir otro esencialmente idéntico y que en última instancia se materializa a través del estándar de diligencia. En otras palabras, aunque el Tribunal niegue que extrae directamente el deber de cuidado de una norma legal, lo cierto es que parece que sí lo hace, para luego determinar solo la discrecionalidad que permite ese deber, o, lo que es lo mismo, el standard of care.

En todo caso, la importancia práctica de esta consideración es muy limitada ya que ninguno de los dos procesos lógicos supone por sí mismo un cambio en la determinación final de la responsabilidad, pues los criterios a utilizar son los mismos. Es decir, cambia

\footnotetext{
${ }^{65}$ Urgenda, cit., párr. 4.53.

${ }^{66} \mathrm{Idem}$, párr. 4.36 (véase punto 2.4.2 apartado B).

${ }^{67}$ Idem, párr. 4.53 a 4.82.
} 
el "qué", no el "cómo", por lo que el primero no varía, independientemente de su calificación jurídica.

Los ya mencionados criterios Kelderluik, por último, se refieren a otros elementos del artículo 162: los tres primeros (naturaleza, previsibilidad y probabilidad) son relativos al daño; el cuarto (naturaleza de los actos del Estado) tiene que ver con el nexo causal; y el quinto versa sobre la onerosidad de las medidas reductoras y se refiere, junto con el sexto (discrecionalidad de los poderes públicos), al standard of care.

\subsection{El daño}

\section{A. Los artículos 2 y 8 del Convenio Europeo de Derechos Humanos}

En su intento por probar la producción de un daño, Urgenda introdujo en la discusión los artículos 2 y 8 del Convenio Europeo de Derechos Humanos (CEDH), que recogen el derecho a la vida y al respeto a la vida privada y familiar, respectivamente ${ }^{68}$. Pretendía con ello suplir la imposibilidad de invocar el derecho a un medio ambiente sano como un derecho humano independiente, dado que no está reconocido como tal en el CEDH.

Como ya se ha comentado ${ }^{69}$, el artículo 305a del Código Civil legitimaba a Urgenda a actuar en defensa de los intereses que promueve. Por este motivo, la demandante pudo actuar en representación de los intereses generales no solo de las generaciones actuales de ciudadanos de los Países Bajos, sino también de los de las generaciones futuras y de otros países ${ }^{70}$, dado que la defensa de estos intereses quedaba dentro de su objeto como fundación (la consecución de una sociedad más sostenible). Ahora bien, los requisitos de esta legitimación distan de los requeridos para invocar derechos recogidos en el CEDH.

En su artículo 34, el Convenio establece como necesario que el demandante sea víctima, directa o indirecta, de la vulneración de un derecho reconocido en este. A pesar de la interpretación amplia de este concepto presente en la jurisprudencia del Tribunal Europeo

\footnotetext{
${ }^{68}$ Convenio Europeo para la Protección de los Derechos Humanos y de las Libertades Fundamentales por los miembros del Consejo de Europa, hecho en Roma el 4 de noviembre de 1950. BOE, núm. 243, de 10 de octubre de 1979.

${ }^{69}$ Véase punto II.2.

${ }^{70}$ Urgenda, cit., párr. 4.4. a 4.10
} 
de Derechos Humanos (TEDH), se excluye la acción popular ${ }^{71}$ en relación con los preceptos del Convenio al considerarse que el artículo 34 establece como condición la afectación concreta de un derecho, de manera que exista una "suficiente relación directa entre el demandante y el daño"72.

Según este criterio, no es posible considerar a Urgenda como víctima, porque "la integridad física de una persona jurídica no puede ser violada ni se puede interferir en su privacidad"73. Es necesario señalar que, aunque en este supuesto concreto no encontremos el mencionado nexo, no en todos los casos que involucren a personas jurídicas tiene por qué ocurrir lo mismo, estando estas legitimadas a actuar ante el TEDH en determinadas circunstancias. En este sentido se pronunció este tribunal en Gorraiz Lizarraga y otros contra España, donde se reconoció la legitimación de una asociación para actuar en defensa de derechos reconocidos en la Convención, siempre que lo haga en relación con daños directos y específicos ${ }^{74}$. Por tanto, aunque en el caso Urgenda la sentencia sea consecuente con la doctrina del Tribunal de Estrasburgo ${ }^{75}$, se debe puntualizar que el hecho de que la parte actora sea una persona jurídica no basta para negar su legitimación, sino que para ello se requiere además que los intereses que represente sean difusos, aspecto en el que no se detiene el Tribunal holandés al dar por hecho que es así.

\section{A.1. El medio ambiente como derecho humano}

A pesar de rechazar la aplicación directa del CEDH, el órgano judicial tuvo en cuenta, de nuevo mediante la interpretación conforme, la relación entre medio ambiente y derechos humanos. Por tanto, reconoció la importancia que tienen los derechos humanos en

\footnotetext{
${ }^{71}$ BOYLE, K., "The European experience: the European Convention on Human Rights", Victoria University of Wellington Law Review, 2009, v. 40 II, pp. 167-177, p. 172.

72 Tribunal Europeo de Derechos Humanos (Sección 3.a). Caso Van Melle y otros contra Países Bajos. Decisión de 29 de septiembre de 2009, p. 5 in fine.

${ }^{73}$ Urgenda, cit., párr. 4.45.

74 Tribunal Europeo de Derechos Humanos (Sección 4. ${ }^{a}$ ). Caso Gorraiz Lizarraga y otros contra España. Sentencia de 27 de abril de 2004.

${ }^{75}$ En concreto, se basa en la decisión de inadmisión de la demanda de Van Melle y otros contra los Países Bajos: Van Melle, cit.
} 
relación con la protección medioambiental, a pesar de las distintas posiciones que ocupan en el derecho internacional ${ }^{76}$.

Principalmente en torno a los artículos 2 y 8 el TEDH ha desarrollado una jurisprudencia que ha consagrado indirectamente un derecho a un medio ambiente sano, para compensar la ausencia de este en el Convenio. En el caso Öneryildiz contra Turquía ${ }^{77}$, el Tribunal de Estrasburgo señaló que el derecho a la vida (artículo 2) obliga al Estado a prevenir determinados riesgos relacionados con el desarrollo de actividades peligrosas. En cuanto al artículo 8, la jurisprudencia originada en el caso López Ostra contra España ${ }^{78}$ viene a afirmar que determinados niveles de contaminación suponen una injerencia no justificada, por cuanto vulneran el principio de proporcionalidad, en el disfrute de la vida privada y familiar ${ }^{79}$. En ambos casos el Estado está obligado, independientemente de que el origen de los perjuicios esté en las actividades de un ente privado ${ }^{80}$. Cabe señalar que la interpretación de la Corte Interamericana de Derechos Humanos es similar en este sentido a la del $\mathrm{TEDH}^{81}$.

Se aprecia en definitiva una interpretación evolutiva del TEDH de ciertos derechos y libertades tendente a conectar estos con la protección medioambiental. Es esta una tendencia que se deja notar también en el ámbito específico del cambio climático, que se relaciona con los derechos humanos a través de tres vertientes: la salud y el bienestar humano, la producción de alimentos y la protección de las generaciones presentes y futuras ${ }^{82}$.

En todo caso, el Tribunal no aplica directamente el CEDH por la condición de persona jurídica de Urgenda y el carácter difuso de los intereses que defiende, teniendo en cuenta además la naturaleza subsidiaria de este instrumento internacional, todo ello ocasionado

\footnotetext{
${ }^{76}$ SALADO OSUNA, A., “Cambio climático y Derechos Humanos”, Giles Carnero, R. (dir.), Cambio climático, energía y derecho internacional: perspectivas de futuro, Aranzadi, Navarra, 2012, pp. 179-194, p. 185.

77 Tribunal Europeo de Derechos Humanos (Gran Sala). Caso Öneryildiz contra Turquía. Sentencia de 30 de noviembre de 2004.

78 Tribunal Europeo de Derechos Humanos (Sala). Caso López Ostra contra España. Sentencia de 9 de diciembre de 1994.

79 TIGROUDJA, H., "El derecho a un medio ambiente sano en la jurisprudencia de la Corte Europea de Derechos Humanos", Revista de Derecho Ambiental, 2009, núm. 3 (3), pp. 155-167, pp. 161-167.

${ }^{80}$ Idem, p. 165.

${ }^{81}$ Idem, p. 161.

${ }^{82}$ SALADO OSUNA, “Cambio climático...”, cit., pp. 185-191.
} 
por el carácter indirecto de la protección medioambiental del TEDH. Esto es una muestra de la problemática derivada de la exclusión del derecho a un medio ambiente sano del CEDH. Dado que la protección medioambiental se sustancia a través de derechos referidos a personas individuales, en casos como el presente, en los que no se puede seguir esa vía, es difícil establecer a qué tipo de realidad jurídica están referidos los daños ${ }^{83}$.

Debido a que la controversia sobre la calificación jurídica del medio ambiente sigue vigente $^{84}$, el Tribunal se abstiene de pronunciarse sobre este asunto ${ }^{85}$, razonando que independientemente de este el daño concurre. Por tanto, dejando de lado la cuestión acerca de a qué están referidos los daños, cabe analizar por qué se considera que el Estado puede ser responsable de ellos.

\section{B. El principio de no causar daños transfronterizos}

Este principio (sic uteretuo ut alienum non laedas), reconocido como consuetudinario a raíz de la jurisprudencia del asunto Gabčikovo-Nagymaros ${ }^{86}$, se traduce en la obligación de los Estados de prevenir daños fuera de su jurisdicción provocados por actividades que se realizan dentro de ella ${ }^{87}$. A pesar de que se sitúa en el plano de la responsabilidad internacional, se puede considerar, como indica Urgenda, que tiene su reflejo en el derecho interno holandés en el artículo 5:37 del Código Civil, que establece la responsabilidad de cualquier persona por inmisiones con origen en su propiedad ${ }^{88}$. De esta manera, se extrapola el mismo mecanismo que calificaría al Estado como responsable

\footnotetext{
${ }^{83}$ RODRÍGUEZ BELTRÁN, J.J., "Los derechos humanos y el medio ambiente", Díkaion: revista de actualidad jurídica, núm. 15, 2006, pp. 80-82.

${ }^{84}$ FERNÁNDEZ EGEA, R.M., "La protección del medio ambiente por el Tribunal Europeo de Derechos Humanos: últimos avances jurisprudenciales”, RJUAM, núm. 31, 2015-I, pp. 163-204.

${ }^{85}$ En el apartado en que trata la naturaleza del daño, el Tribunal habla de "irreversibles y serias consecuencias para el hombre y el medio ambiente", por lo que no se detiene en la caracterización del daño ni de la realidad jurídica lesionada. Véase Urgenda, cit., párr. 4.64.

${ }^{86}$ Corte Internacional de Justicia. Caso Proyecto Gabčikovo-Nagymaros (Hungría/Eslovaquia). Sentencia de 25 de septiembre de 1997, I.C.J. Reports 1997, p. 7.

${ }^{87}$ FERNÁNDEZ EGEA, R.M., "El deber de protección frente a los efectos del cambio climático, a propósito de la sentencia del Tribunal de La Haya (Rechtbank Den Haag) de 24 de junio de 2015", Aquiescencia: blog de derecho internacional de Carlos Espósito, 21 de julio de 2015. Disponible en: https://aquiescencia.net/2015/07/21/el-deber-de-proteccion-frente-a-los-efectos-del-cambio-climaticopor-rosa-fernandez-egea/.

${ }^{88}$ Summons, cit., párr. 261 a 264.
} 
a nivel internacional también a la decisión sobre si existe responsabilidad en la esfera nacional ${ }^{89}$.

Con todo, es imprescindible que el perjuicio se haya producido a consecuencia de una conducta de la parte demandada.

\subsection{El nexo causal}

Para afirmar la existencia de relación de causalidad, el Tribunal desmontó el argumento de que no se puede identificar al Estado como causante de los daños que se le imputan. Este se fundamentaba en que la aportación de los Países Bajos a dichos daños es solo una "gota en el océano" ( "drop in the ocean" argument), es decir, en que su contribución al fenómeno del cambio climático es insignificante ${ }^{90}$.

Ante esto, la Corte recurrió a la doctrina establecida por el Tribunal de Justicia de la Unión Europea en Minas de potasa ${ }^{91}$. Esta establece que, cuando el daño sea el resultado de la acción conjunta de varias fuentes, la responsabilidad se debe repartir a prorrata, de manera que cada parte responda por lo que proporcionalmente le corresponde ${ }^{92}$.

En el caso Urgenda, esta regla permite afirmar la existencia de relación causal entre la eventual omisión del deber de cuidado y el resultado del cambio climático al estar aquella referida solo a la parte proporcional del daño atribuible al Estado.

\footnotetext{
${ }^{89}$ Sobre este tema, es pertinente señalar que, sobre la base del principio de no causar daños transfronterizos, se puede considerar responsable al Estado incluso por la no realización de una evaluación de impacto ambiental, como señaló la Corte Internacional de Justicia en Pulp Mills, lo cual implica una noción amplia del concepto de daño que refuerza el razonamiento del Tribunal en Urgenda acerca de este punto. Además, en Pulp Mills se pone en relación este principio con el de prevención, que, como se verá más adelante, es de capital importancia en Urgenda. Véase: Corte Internacional de Justicia. Caso Plantas de celulosa en el río Uruguay (Argentina/Uruguay). Sentencia de 20 de abril de 2010, I.C.J. Reports 2010, p. 14, párr. 204. Sobre la aplicación del principio de prevención en dicha sentencia, véase KAZHDAN, D., "Precautionary Pulp: Pulp Mills and the Evolving Dispute between International Tribunals over the Reach of the Precautionary Principle”, Ecology Law Quarterly, 2011, vol. 38.

${ }^{90}$ Urgenda, cit., 4.79.

${ }^{91}$ Tribunal de Justicia de la Unión Europea. Caso Handelskwekerij G. J. Bier BV contra Mines de potasse d'Alsace SA (C-21/76, ECLI:EU:C:1976:166). Sentencia de 30 de noviembre de 1976.

${ }^{92}$ Urgenda Foundation. Statement of reply. 21 de mayo de 2015. Párr. 249-254. Disponible en: http://www.urgenda.nl/en/climate-case/
} 


\subsection{La culpabilidad}

A. La incidencia de los principios de objetivación, prevención y precaución

Hablar de culpabilidad significa hablar de diligencia, pues la intensidad con que se deba observar una obligación define la concurrencia o no de culpa, lo cual depende de si se debía actuar y de si se podía ${ }^{93}$. La determinación de la diligencia exigible al Estado es la cuestión clave en la sentencia pues, como ya hemos señalado, es imprescindible para afirmar o negar la existencia de un deber de cuidado.

Para ello, se requiere una reflexión relativa a los principios de prevención y precaución y al efecto que en ellos tiene el de objetivación. De esos principios, los dos primeros constituyen la traducción al plano internacional del concepto de diligencia debida. El primero de ellos insta al Estado a actuar frente a riesgos ciertos, e incluye obligaciones relativas a la disponibilidad de instrumentos de prevención y al uso de dichos instrumentos, así como implica el establecimiento de mecanismos de reparación cuya existencia y eficacia también presupone ${ }^{94}$. El principio de precaución, por su parte, está relacionado con los riesgos inciertos. Esto no quiere decir que el nivel de diligencia que impone sea necesariamente más laxo, dado que la incertidumbre puede exigir que el cuidado sea incluso mayor que en aquellos casos en los que existe una gran certeza. En general, supone añadir a la acción protectora ciertos deberes acerca de la disipación de la incertidumbre, la cual precisa el mayor desarrollo técnico posible, además de otras obligaciones como el fomento de la participación social en la toma de decisiones del sector público 95 .

Por estas razones, la elección entre uno u otro influye de manera determinante en el establecimiento del standard of care. En dicha elección interviene el principio de objetivación de la tutela ambiental, que generalmente conlleva un aumento del campo de aplicación del principio de prevención respecto del de precaución; tal y como señala el

\footnotetext{
${ }^{93}$ VAN DAM, European..., cit., pp. 184-185.

94 JIMÉNEZ DE PARGA Y MASEDA, P., “Análisis del principio de precaución en Derecho internacional público: perspectiva universal y perspectiva regional europea”, Política y Sociedad, 2003, vol. 40, núm. 3, pp. 7-22, p. 16.

95 DRNAS DE CLÉMENT, Z., "Fuentes del Derecho Internacional del Medio Ambiente”, Sindico, F., Fernández Egea, R.M. y Borrás Pentinat, S. (dirs.), Derecho Internacional del Medio Ambiente: Una visión desde Iberoamérica, CMP Publishing Ltd, Londres, 2011, pp. 31-71, pp. 61-66.
} 
Principio 15 de la Declaración de Río sobre el Medio Ambiente y el Desarrollo ${ }^{96}$, la falta de certeza absoluta no excluye la posibilidad de calificar un riesgo como cierto, bastando un amplio consenso científico para ello. Una interpretación amplia de esta disposición implica considerar un número mayor de situaciones como objetivamente peligrosas, lo que conlleva lógicamente que la acción preventiva gane espacio dado que la certeza del riesgo es el criterio para optar por prevención o precaución.

En su escrito de contestación, Urgenda propone una interpretación evolutiva del citado Principio 15 a la vista del avance de la técnica en este campo. Citando a M. FAURE, plantea que, respecto al cambio climático, "parece no haber ya incertidumbre alguna acerca de las posibles consecuencias (como un requisito para aplicar este principio). Es, por tanto, el principio de prevención el que ahora obliga a actuar" ${ }^{\text {"97 }}$. Cabe recordar que también en el ámbito europeo ${ }^{98}$ la Comunicación de la Comisión sobre el recurso al principio de precaución, de 2 de febrero del 2000, afirma que solo entrará en juego el principio de precaución cuando se identifique un efecto potencialmente dañoso cuya evaluación científica no arroje certidumbre sobre la verificación del riesgo ${ }^{99}$, por lo que, al contrario, cabe aplicar el de prevención cuando exista certeza suficiente. El nivel de diligencia en el caso sería entonces, según la interpretación de la demandante, el derivado de este último principio, que implicaría una reducción de emisiones suficiente como para evitar que los efectos del cambio climático sean irreparables ${ }^{100}$.

No obstante, a pesar de que la Corte parece seguir esta interpretación partiendo también de la consideración del cambio climático como un riesgo seguro ${ }^{101}$, acaba por aplicar el principio de precaución. La diferencia con respecto al planteamiento de la demandante radica en que el Tribunal pone en relación la certeza del riesgo con la de la eficacia de las medidas a ejecutar ${ }^{102}$. Debido a que no es posible predicar dicha certeza, opta por utilizar

\footnotetext{
${ }^{96}$ Declaración de Río sobre el Medio Ambiente y el Desarrollo, Conferencia de las Naciones Unidas sobre el Medio Ambiente y el Desarrollo, aprobada en Estocolmo el 16 de junio de 1972.

${ }^{97}$ Statement of reply, cit., párr. 428.

${ }^{98}$ Es conveniente recordar que el principio de precaución aparece mencionado en el artículo 191 del Tratado de Funcionamiento de la Unión Europea como principio que ha de fundamentar la política de la Unión.

${ }^{99}$ Comisión de las Comunidades Europeas, Comunicación de la Comisión sobre el recurso al principio de precaución. Bruselas, 2 de febrero del $2000 \operatorname{COM(2000)} 1$ final.

${ }^{100}$ Véase el punto 2.3 ("Hechos: el estado actual de la ciencia").

${ }^{101}$ Ibidem.

${ }^{102}$ Urgenda, cit., párr.
} 
el principio de precaución para enjuiciar las actuaciones llevadas a cabo por el Estado. Aunque esto no aparece especificado en la sentencia, resulta claro cuando se analiza el modo concreto en que se desarrolla dicho juicio, que es el propio del principio de precaución.

B. La aplicación del principio de precaución. El análisis coste-beneficio

A la hora de aplicar el principio precautorio, la Corte hace referencia a la existencia de medidas eficaces disponibles. Una vez resuelta esa cuestión, se pronuncia sobre la relación entre coste y beneficio de dichas medidas ${ }^{103}$. Esta solución es conforme con aquellas opiniones que, abogando por un enfoque intermedio, han tratado de zanjar el debate sobre la primacía del principio de precaución (entendido de manera amplia) o del análisis coste-beneficio en relación con la evaluación de situaciones de riesgo ${ }^{104}$. Dicha solución pasa por un análisis coste-beneficio precautorio que, como en el caso, supone ponderar el aumento de bienestar que supondría evitar el riesgo (beneficio) en relación con la onerosidad de las medidas (coste), tomando como referencia el peor escenario posible (prevención), que en esta ocasión sería el de la producción de daños irreparables ${ }^{105}$. Además, es fundamental destacar que se invierte la carga de la prueba, de manera que se considera que es el Estado quien debe probar que no existen medidas a su alcance más allá de las realizadas o bien que estas son las más eficientes ${ }^{106}$.

En cuanto a la disponibilidad de medidas eficaces, aunque el Estado puede concretar su política en materia climática de la manera que crea más conveniente, debe hacerlo de forma apropiada y efectiva ${ }^{107}$. En respuesta a qué se considera una actuación apropiada para prevenir las consecuencias del cambio climático, la Corte sostiene que no bastan las medidas de adaptación, pues eventualmente devendrían desproporcionadamente costosas

\footnotetext{
${ }^{103}$ Urgenda, cit., párr. 4.67 a 4.82.

${ }^{104}$ Sobre este tema, véase KAHAN, D., SLOVIC, P., BRAMAN, D. y GASTIL, J., "Fear of Democracy: A cultural evaluation of Sunstein on risk", Harvard Law Review, 2006, núm. 119, p. 1071; SUNSTEIN, C., "Misfearing: A reply", Harvard Law Review, 2006, núm. 119, p. 1110. Ambos artículos discuten sobre SUNSTEIN, C., Laws of Fear: Beyond the precautionary principle, Cambridge University Press, Cambridge, 2006.

${ }^{105}$ DRIESEN, D.M., "Cost-benefit analysis and the precautionary principle: can they be reconciled?", Michigan State Law Review, 2013, issue 3, pp. 771-826, pp. 812-825.

${ }^{106}$ ROY, "Situating Urgenda...", cit., pp. 20-30.

${ }^{107}$ Urgenda, cit., párr. 4.74.
} 
sin mitigación ${ }^{108}$. De esta manera, encontramos un primer límite a la libertad de decisión del Estado en relación con el modo de actuación.

El Estado discute precisamente la eficacia de las acciones que reclama Urgenda sobre la base del fenómeno conocido como waterbed effect o carbon leakage (fuga de carbono). Con este término se da nombre al incremento en las emisiones que se produce en el exterior de un país a consecuencia del fortalecimiento de las políticas de protección ambiental en dicho Estado ${ }^{109}$. Así, se cuestiona la existencia de medidas eficaces al alcance de los Países Bajos, lo cual el Tribunal considera infundado. En este sentido, la Comisión Europea - a cuya opinión se remite la sentencia - niega la existencia de evidencia alguna que respalde la tesis de la fuga de carbono, al menos a gran escala ${ }^{110}$.

El Tribunal también valora la existencia de causas que exceptúen la culpa del Estado. La primera de ellas podría ser la imposibilidad material de ejecutar las acciones requeridas, como ocurriría si los costes a asumir fuesen completamente desproporcionados. En relación con este punto, la parte demandada alegó la pérdida de competitividad económica que consideraba que las medidas exigidas por la actora producirían. El Tribunal desestimó este motivo por falta de claridad y, consecuentemente, de prueba suficiente, aunque reconoció que podría haber sido un argumento a tener en cuenta al contabilizar los "costes" "111.

De igual manera, se tiene en cuenta una eventual imposibilidad formal de ajustarse a la diligencia debida, que se refiere a la aplicación de los objetivos de reducción fijados en el marco del régimen de comercio de derechos de emisión de gases de efecto invernadero de la Unión Europea (ETS). La parte demandada argumentó que el endurecimiento de las medidas establecidas a nivel europeo no está permitido ${ }^{112}$, interpretando que el legislador europeo pretende en este ámbito una armonización total. El Tribunal, remitiéndose a lo

\footnotetext{
108 Idem, párr. 4.75.

${ }^{109}$ Véase REINAUD, J., "Issues behind Competitiveness and Carbon Leakage: Focus on Heavy Industry", International Energy Agency Information paper, octubre de 2008.

${ }^{110}$ Véase Comisión Europea, Documento de trabajo de los servicios de la Comisión, resumen de la evaluación de impacto que acompaña a la Comunicación de la Comisión al Parlamento Europeo, al Consejo, al Comité Económico y Social Europeo y al Comité de las Regiones: Un marco estratégico en materia de clima y energía para el periodo de 2020 a 2030. Bruselas, 22 de enero de 2014, SWD(2014) 16 final.

${ }^{111}$ Urgenda, cit., párr. 4.82.

${ }^{112}$ Idem, párr. 4.69.
} 
alegado por Urgenda ${ }^{113}$, contradijo esta tesis ${ }^{114}$; entendió que las directivas de la Unión Europea en este sentido deben observarse en clave de armonización mínima, de manera que los Estados miembros pueden mostrarse más estrictos que la $\mathrm{UE}^{115}$, pues lo que esta establece son mínimos comunes ${ }^{116}$.

De todo lo expuesto hasta ahora la Corte concluyó que el Estado tiene a su disposición líneas de actuación material y formalmente eficaces y a su alcance. Además, no resulta irracional exigir al Estado que las ponga en marcha. En relación con estas medidas, cabe mencionar que la Comunicación de la Comisión del año 2000, junto con los supuestos en que es de aplicación el principio de proporcionalidad, recoge una serie de directrices que condicionan la validez de las actuaciones del Estado. Así, estas deberían ser proporcionales en relación con la magnitud del riesgo, no discriminatorias, coherentes (en relación con otras adoptadas en situaciones similares) y tener en cuenta la evolución científica, además de ser establecidas, también, conforme a un análisis coste-beneficio ${ }^{117}$. Aunque el Tribunal no lo explicite, debemos entender que las actuaciones que, a su parecer, el Estado tiene a su alcance podrían eventualmente cumplir estos requisitos una vez concretadas.

En este punto, se señala que la autonomía para elegir la manera de combatir el cambio climático también se ve limitada por el principio de responsabilidades comunes pero diferenciadas. Este principio constituye un mandato de cooperación entre Estados, si bien hay que tener en cuenta que estos "han contribuido en distinta medida a la degradación del medio ambiente mundial", tal y como señala el principio 7 de la Declaración de Río. Esto, razona el Tribunal en el caso Urgenda, supone que los países del anexo I (y Países Bajos entre ellos) deben llevar a cabo políticas más comprometidas con la prevención del

\footnotetext{
113 Statement of reply, cit., párr. 425.

${ }^{114}$ Urgenda, cit., párr. 4.80.

${ }^{115}$ Decisión 406/2009/CE del Parlamento Europeo y del Consejo sobre el esfuerzo de los Estados miembros para reducir sus emisiones de gases de efecto invernadero a fin de cumplir los compromisos adquiridos por la Comunidad hasta 2020, Diario Oficial de la Unión Europea, núm. L140, de 23 de abril de 2009, pp. 136-148, punto 17 de las consideraciones preliminares.

116 JANS, J.H. y VEDDER, H.H.B., European Environmental Law, 3. a ed., Europa Law Publishing, Groningen, 2008, pp. 98-104.

${ }^{117}$ Comisión de las Comunidades Europeas, Comunicación de 2 de febrero del 2000, cit.
} 
cambio climático. En último lugar, argumenta que la carga de dichas políticas no debería recaer sobre las generaciones futuras en mayor medida que sobre las presentes ${ }^{118}$.

Una vez hechas estas consideraciones, el Tribunal lleva a cabo una ponderación entre coste y beneficio stricto sensu. La apreciación que realiza aquí se refiere en concreto a la eficiencia de las medidas adoptadas por los Países Bajos. Sobre la base de los últimos avances tecnológicos, la Corte concluye que la parte demandada no ha sido capaz de demostrarla, puesto que la eficiencia de la mitigación depende en gran parte de que esta se inicie cuanto antes ${ }^{119}$.

En resumen, el razonamiento del Tribunal respecto a la culpabilidad se puede dividir en dos partes. En primer lugar, matiza la certeza que aportan la ciencia y la técnica, de manera que descarta la aplicación del principio de prevención. Este matiz se refiere no a la previsibilidad del daño, sino a la certeza acerca de la efectividad de las medidas para evitarlo. En segundo lugar, ante la falta de certeza no trata de establecer una precaución absoluta, sino que la sustancia a través del worst-case scenario, respecto al cual realiza su análisis de coste-beneficio. Este escenario es el establecido en los hechos sobre la base del estado actual de la ciencia.

El planteamiento queda claramente expresado en la siguiente cita extraída de la sentencia: Además, el Estado no puede posponer el tomar medidas precautorias basándose en la sola razón de que aún no existe certeza científica acerca del efecto preciso de las medidas. Al contrario, cabe aquí una ratio coste-beneficio. Finalmente, el Estado tendrá que basar sus acciones en el principio de "prevenir mejor que curar" 120.

Sobre la base de estas consideraciones, el Tribunal sentenció que el Estado tenía un deber de cuidado relativo a la reducción de emisiones, por lo que lo condenó a actuar para que esta se produjese $^{121}$.

\footnotetext{
${ }^{118}$ Urgenda, cit., párr. 4.76.

${ }^{119}$ Idem, párr. 4.73.

${ }^{120}$ Idem, párr. 4.76, in fine. Cursiva añadida. Traducción propia.

${ }^{121}$ Idem, párr. 4.103.
} 
C. Los efectos políticos de la decisión y la separación de poderes

El método elegido para determinar el standard of care plantea problemas relativos a los efectos políticos que lleva aparejados. La Corte sigue otras sentencias en materia medioambiental como las estadounidenses Massachusetts contra EPA y AEP contra Connecticut, en las que se traza una distinción entre aquellas decisiones puramente políticas y las que simplemente tengan consecuencias políticas indirectas, quedando solo las primeras fuera de la competencia de los tribunales ${ }^{122}$.

A la vista de lo dicho anteriormente, es discutible, sin embargo, que el Tribunal se limitase a emitir una decisión judicial con implicaciones políticas indirectas. En efecto, al realizar un juicio sobre el coste-beneficio de las medidas a adoptar se pronunció sobre la adecuación y la eficacia de la actuación estatal. El Tribunal, al considerar que no se había probado la suficiencia de las medidas del ejecutivo, no puede prescindir de efectuar un juicio paralelo de estas que parece más de oportunidad que estrictamente jurídico. Dicho juicio resulta cuestionable, pues se podría afirmar que está en condiciones de anular completamente el margen de apreciación que tiene el Estado al negar su capacidad volitiva y afectar a la separación de poderes ${ }^{123}$.

No obstante, la discrecionalidad del Estado no puede constituir un impedimento absoluto para que este tipo de casos sea juzgado. El Tribunal recuerda que en los Países Bajos no se suele hablar de una estricta separación de poderes sino más bien de un equilibrio entre estos de forma que no exista primacía de unos sobre otros ${ }^{124}$. Estas consideraciones generales dejan la cuestión abierta, lo que en consecuencia da lugar a una gran controversia $^{125}$ cuyo análisis excede los límites del presente trabajo.

\footnotetext{
${ }^{122}$ Estados Unidos, Tribunal Supremo. Caso Massachusetts contra EPA. Sentencia de 2 de abril de 2007; Estados Unidos, Tribunal Supremo. Caso AEP contra Connecticut. Sentencia de 20 de junio de 2011.

${ }^{123}$ Por ejemplo, BERGKAMP, L., "Het Haagse klimaatvonnis. Rechterlijke onbevoegdheid en de negatie van het causaliteitsvereiste", Nederlands Juristenblad, 2015, núm. 1676, pp. 2278-2288, citado en THURLINGS, T.J., "The Dutch climate case: some legal considerations", 28 de noviembre de 2015. Disponible en Social Research Network: http://ssrn.com/abstract=2696343:

En consecuencia, en la medida en que esta decisión judicial es celebrada como una victoria para el clima, es también una amenaza para el imperio de la ley y la democracia constitucional. Ante la petición de cualquier clase de grupos de acción, los tribunales de lo civil podrían elaborar políticas respecto a cualquier riesgo [...]. Esto podría conducir a políticas apoyadas solo por pequeñas minorías e implicar altos costes de conformidad; consecuentemente, bien podría desencadenar una reacción política opuesta.

${ }^{124}$ Urgenda, cit., párr. 4.94 a 4.102.

125 Véase BERGKAMP, “Het Haagse...”, cit.; ENNEKING, L. y DE JONG, E., "Regulering van Onzekere Risico’s via Public Interest Litigation”, Nederlands Juristenblad, 2014, núm. 23, pp. 1542-51,
} 


\section{CONCLUSIONES}

En el presente estudio se han considerado individualmente los distintos razonamientos desarrollados en la sentencia de 24 de junio de 2015 sobre el caso Urgenda contra Países Bajos. Sin embargo, es necesario, para concluir, conectarlos desde una perspectiva general.

En primer lugar, vemos que no se plantea discusión alguna acerca de los hechos, esto es, acerca de la certeza de la existencia del fenómeno del cambio climático, y que la cuestión se desplaza al ámbito puramente jurídico. Ya en dicho ámbito, y en concreto en el de la responsabilidad civil extracontractual, el Tribunal centra la controversia en el estándar de diligencia puesto que de este depende la existencia o no de un deber de cuidado. En último lugar, el análisis de dicho estándar se fundamenta en un juicio sobre la eficiencia de la actuación estatal contra el cambio climático.

Por supuesto, este último juicio plantea profundos problemas en relación con la separación de poderes. Sin embargo, dejando estos de lado por un momento, no puede sino subrayarse la forma en que el Tribunal circunscribe el núcleo de la controversia del caso a esta cuestión. Es precisamente este el aspecto que puede resultar de más interés, puesto que se establece una vía para reconducir el debate general sobre la responsabilidad del Estado por daños derivados del cambio climático hacia una discusión sobre la discrecionalidad de que este goza en dicho ámbito. Se configura así un nuevo marco dialéctico, establecido en zonas más grises del ordenamiento jurídico, de forma que la responsabilidad estatal no queda limitada de manera tan clara. En este sentido, este razonamiento constituye una herramienta de gran utilidad para aquellos actores que, en el ámbito de la litigación ambiental, tratan de conseguir una mayor acción por parte de los Estados.

En todo caso, no es posible tampoco pasar por alto las dificultades que plantea la cuestión del principio de separación de poderes, y habrá que comprobar si es posible armonizar esta nueva vía con dicho principio. De cómo se resuelva este tema dependerá el que estemos ante un caso de referencia con vistas a asuntos futuros o bien ante una mera excepción.

citado en VAN ZEBEN, "Establishing a...”, cit., pp. 353-354; ROY, “Situating Urgenda...", cit., pp. 28 32. 
En conclusión, podemos afirmar que, a pesar de que la eficacia concreta en el caso de este razonamiento se pueda ver comprometida conforme avance el proceso en instancias superiores, el caso Urgenda supone un nuevo paso en el debate acerca de la responsabilidad del Estado en este campo y como tal ha de ser tenido en cuenta.

\section{BIBLIOGRAFÍA}

\section{Selección de obras y artículos}

ANTUNES, T., "The 'normative adaptation' to climate-related events", Giles Carnero, R. (dir.), Cambio climático, energía y Derecho Internacional, perspectivas de futuro, Aranzadi, Navarra, 2012, pp. 65-78.

BERMEJO, R. y EGUILLOR, L., “COP 21 ¿Éxito o fracaso?”, Centro de Documentación Hegoa, Boletín de recursos de información, núm. 45, diciembre de 2015, pp. 1-8.

BETLEM, G. y NOLLKAEMPER, A., "Giving effect to Public International Law and European Community Law before domestic courts. A comparative analysis of the practice of consistent interpretation”, European Journal of International Law, 2003, vol. 14, núm. 3, pp. 569-589.

BORRÁS PENTINAT, S., "Los litigios climáticos: Entre la tutela climática y la fiscalización de las responsabilidades por daños climáticos", Giles Carnero, R. (dir.), Cambio climático, energía y Derecho Internacional: perspectivas de futuro, Aranzadi, Navarra, 2012, pp. 91-104.

BOYLE, K., "The European experience: the European Convention on Human Rights", Victoria University of Wellington Law Review, 2009, v. 40 II, pp. 167-177.

DRIESEN, D.M., "Cost-benefit analysis and the precautionary principle: can they be reconciled?", Michigan State Law Review, 2013, issue 3, pp. 771-826.

DRNAS DE CLÉMENT, Z., "Fuentes del Derecho Internacional del Medio Ambiente", Sindico, F., Fernández Egea, R.M. y Borrás Pentinat, S. (dirs.), Derecho Internacional del Medio Ambiente: Una visión desde Iberoamérica, CMP Publishing Ltd, Londres, 2011, pp. 31-71. 
FERNÁNDEZ EGEA, R.M., "La protección del medio ambiente por el Tribunal Europeo de Derechos Humanos: últimos avances jurisprudenciales", RJUAM, núm. 31, 2015-I, pp. 163-204.

GILES CARNERO, R., "El Protocolo de Kioto como modelo de gestión ambiental global”, Remiro Brotóns, A. y Fernández Egea, R.M. (dirs.), El cambio climático en el Derecho Internacional y Comunitario, Fundación BBVA, Bilbao, 2009, pp. 27-60.

JANS, J.H. y VEDDER, H.H.B., European Environmental Law, 3. a ed., Europa Law Publishing, Groningen, 2008.

JIMÉNEZ DE PARGA y MASEDA, P., “Análisis del principio de precaución en Derecho internacional público: perspectiva universal y perspectiva regional europea”, Política y Sociedad, 2003, vol. 40, núm. 3, pp. 7-22.

JUSTE RUIZ, J., "El régimen internacional para combatir el cambio climático en la encrucijada", Giles Carnero, R. (dir.), Cambio climático, energía y derecho internacional: perspectivas de futuro, Aranzadi, Navarra, 2012, pp. 37-49.

KAHAN, D., SLOVIC, P., BRAMAN, D. y GASTIL, J., "Fear of Democracy: A cultural evaluation of Sunstein on risk”, Harvard Law Review, 2006, núm. 119, p. 1071.

KAZHDAN, D., "Precautionary Pulp: Pulp Mills and the Evolving Dispute between International Tribunals over the Reach of the Precautionary Principle", Ecology Law Quarterly, 2011, vol. 38.

LIN, J.S.W., "The first successful climate negligence case: A comment on Urgenda Foundation v. The State of the Netherlands", Climate Law (Brill Publishing), 2015, v. 5 núm. 1, pp. 65-81.

PASPATI, E., "The output of the Durban climate change negotiations: a first critical approach", Mepielan eBulletin, 22 de febrero de 2012. Disponible en: http://www.mepielanebulletin.gr/default.aspx?pid=18\&CategoryId=8\&ArticleId=93\&Article=The-Outputof-the-Durban-Climate-Change-Negotiations-A-First-Critical-Approach.

PEÑA CHACÓN, M., "Los principios de objetivación de la tutela a ambiental e irreductibilidad de espacios sometidos a régimen especial de protección y su relación con la prohibición de retroceso", Medio Ambiente y Derecho: Revista electrónica de derecho ambiental, núm. 25, diciembre de 2013. 
PEYRÓ LLOPIS, A., "Los mecanismos de control del cumplimiento de las obligaciones previstas en el Protocolo de Kioto”, Remiro Brotóns, A. y Fernández Egea, R.M. (dirs.), El cambio climático en el Derecho Internacional y Comunitario, Fundación BBVA, Bilbao, 2009, pp. 61-85.

PURNHAGEN, K., "Towards a regime of emission litigation based on science", Wageningen Working Papers in Law and Governance, Law and Governance Group, 2015/10.

REINAUD, J., "Issues behind Competitiveness and Carbon Leakage: Focus on Heavy Industry, International Energy Agency Information paper, octubre de 2008.

RODRÍGUEZ BELTRÁN, J.J., "Los derechos humanos y el medio ambiente”, Díkaion: revista de actualidad jurídica, núm. 15, 2006, pp. 80-82.

ROY, S., "Situating Urgenda versus the Netherlands within comparative climate change litigation", Journal of Energy \& Natural Resources Law, v. 34, 2016.

SALADO OSUNA, A., "Cambio climático y Derechos Humanos", Giles Carnero, R. (dir.), Cambio climático, energía y derecho internacional: perspectivas de futuro, Aranzadi, Navarra, 2012, pp. 179-194.

SUNSTEIN, C., "Misfearing: A reply”, Harvard Law Review, 2006, núm. 119, p. 1110.

SUNSTEIN, C., Laws of Fear: Beyond the precautionary principle, Cambridge University Press, Cambridge, 2006.

THURLINGS, T.J., "The Dutch climate case: some legal considerations", 28 de noviembre de 2015. Disponible en Social Research Network: http://ssrn.com/abstract=2696343.

TIGROUDJA, H., "El derecho a un medio ambiente sano en la jurisprudencia de la Corte Europea de Derechos Humanos", Revista de Derecho Ambiental, 2009, núm. 3 (3), pp. 155-167.

VAN DAM, C., European Tort Law, 1. a ed., Oxford University Press Inc., Nueva York, 2007.

VAN MAANEN, G., TOWNEND, D. y TEFFERA, A., "The dutch 'Cellar Hatch' judgment as a landmark case for tort law un Europe: a brief comparison with English, 
French and German law with a Law and Economics flavour", European Review of Private Law, 2008, v. 16, issue 5, pp. 871-889.

VAN ZEBEN, J., "Establishing a governmental duty of care for climate change mitigation: Will Urgenda turn the tide?”, Transnational Environmental Law, 2015, núm. 4, pp. 339-357.

\section{Normativa}

Acuerdo de París, 21. ${ }^{\text {er }}$ período de sesiones de la Conferencia de las Partes, Convención Marco sobre el Cambio Climático de las Naciones Unidas, hecho en París el 12 de diciembre de 2015.

Carta Mundial de la Naturaleza, Resolución 37/7 de la Asamblea General de las Naciones Unidas, de 28 de octubre de 1982.

Convenio Europeo para la Protección de los Derechos Humanos y de las Libertades Fundamentales por los miembros del Consejo de Europa, hecho en Roma el 4 de noviembre de 1950. BOE, núm. 243, de 10 de octubre de 1979.

Decisión 406/2009/CE del Parlamento Europeo y del Consejo sobre el esfuerzo de los Estados miembros para reducir sus emisiones de gases de efecto invernadero a fin de cumplir los compromisos adquiridos por la Comunidad hasta 2020, Diario Oficial de la Unión Europea, núm. L140, de 23 de abril de 2009, pp. 136-148.

Declaración de Río sobre el Medio Ambiente y el Desarrollo, Conferencia de las Naciones Unidas sobre el Medio Ambiente y el Desarrollo, aprobada en Estocolmo el 16 de junio de 1972.

Directiva 2003/87/CE del Parlamento Europeo y del Consejo, de 13 de octubre de 2003, por la que se establece un régimen para el comercio de derechos de emisión de gases de efecto invernadero en la Comunidad y por la que se modifica la Directiva 96/61/CE del Consejo, Diario Oficial de la Unión Europea, núm. L275, de 25 de octubre de 2003, p. 32.

Directiva 2008/50/CE del Parlamento Europeo y del Consejo, de 21 de mayo de 2008, relativa a la calidad del aire ambiente y a una atmósfera más limpia en Europa, Diario Oficial de la Unión Europea, núm. L152, de 11 de junio de 2008, pp. 1-44. 
Países Bajos. Código Civil de 21 de marzo de 1804. Boletín Oficial del Reino de los Países Bajos (Staatsblad van het Koninkrijk der Nederlanden), núm. 30, de 3 de septiembre de 1807. Una traducción al inglés se puede encontrar en: http://www.dutchcivillaw.com/civilcodegeneral.htm

Países Bajos. Constitución del Reino de los Países Bajos, publicada el 29 de agosto de 2008 por el Ministro del Interior, Relaciones del Reino y Asuntos Constitucionales.

Tratado de Funcionamiento de la Unión Europea, entre S.M. el Rey de los Belgas, el Presidente de la República Federal de Alemania, el Presidente de la República Francesa [....], hecho en Roma el 25 de marzo de 1957. Diario Oficial de la Unión Europea, núm. 83, de 30 de marzo de 2010, pp. 47-199.

\section{Jurisprudencia nacional e internacional}

Corte Internacional de Justicia. Caso Plantas de celulosa en el río Uruguay (Argentina/Uruguay). Sentencia de 20 de abril de 2010, I.C.J. Reports 2010, p. 14.

Corte Internacional de Justicia. Caso Proyecto Gabčikovo-Nagymaros (Hungría/Eslovaquia). Sentencia de 25 de septiembre de 1997, I.C.J. Reports 1997, p. 7. Estados Unidos, Tribunal Supremo. Caso AEP contra Connecticut. Sentencia de 20 de junio de 2011.

Estados Unidos, Tribunal Supremo. Caso Massachusetts contra EPA. Sentencia de 2 de abril de 2007.

Países Bajos, Tribunal del Distrito de La Haya (Sala de lo Mercantil). Caso Urgenda contra Países Bajos. Sentencia de 24 de junio de 2015 (ECLI:NL:RBDHA:2015:7196).

Países Bajos, Tribunal Supremo (Sala de lo Civil). Caso Kelderluik. Sentencia de 5 de noviembre de 1965 (ECLI:NL:HR:1965:AB7079).

Países Bajos, Tribunal Supremo (Sala de lo Civil). Caso Vrede y otros contra Países Bajos. Sentencia de 6 de febrero de 2004 (ECLI:NL:HR:2004:AN8071).

Países Bajos, Tribunal Supremo. Caso Spoorwegstaking. Sentencia de 30 de mayo de 1986 (ECLI:NL:HR:1986:AC9402).

Países Bajos, Tribunal Supremo. Sentencia de 18 de abril de 1995 (ECLI:NL:HR:1995:AD4656). 
Tribunal de Justicia de la Unión Europea. Caso Becker (C-8/81, ECLI:EU:C:1982:7). Sentencia de 19 de enero de 1982.

Tribunal de Justicia de la Unión Europea. Caso Handelskwekerij G. J. Bier BV contra Mines de potasse d'Alsace SA (C-21/76, ECLI:EU:C:1976:166). Sentencia de 30 de noviembre de 1976.

Tribunal de Justicia de la Unión Europea. Caso Janecek contra Freistaat Bayern (C237/07, ECLI:EU:C:2008:447). Sentencia de 25 de julio de 2008.

Tribunal de Justicia de la Unión Europea. Caso Lütticke (C-57/65, ECLI:EU:C:1966:34). Sentencia de 16 de junio de 1966.

Tribunal de Justicia de la Unión Europea. Caso Ratti (C-148/78, ECLI:EU:C:1979:110). Sentencia de 5 de abril de 1979.

Tribunal de Justicia de la Unión Europea. Caso Salgoil (C-13/68, ECLI:EU:C:1968:54). Sentencia de 19 de diciembre de 1968.

Tribunal de Justicia de la Unión Europea. Caso Van Gend en Loos (C-26/62, ECLI:EU:C:1963:1). Sentencia de 5 de febrero de 1963.

Tribunal Europeo de Derechos Humanos (Gran Sala). Caso Öneryildiz contra Turquía. Sentencia de 30 de noviembre de 2004.

Tribunal Europeo de Derechos Humanos (Sala). Caso López Ostra contra España. Sentencia de 9 de diciembre de 1994.

Tribunal Europeo de Derechos Humanos (Sección 3. a). Caso Van Melle y otros contra Países Bajos. Decisión de 29 de septiembre de 2009.

Tribunal Europeo de Derechos Humanos (Sección 4. ${ }^{a}$ ). Caso Gorraiz Lizarraga y otros contra España. Sentencia de 27 de abril de 2004.

\section{Otros recursos}

Comisión de las Comunidades Europeas, Comunicación de la Comisión sobre el recurso al principio de precaución. Bruselas, 2 de febrero del 2000 COM(2000) 1 final.

Comisión Europea, Documento de trabajo de los servicios de la Comisión, resumen de la evaluación de impacto que acompaña a la Comunicación de la Comisión al Parlamento 
Europeo, al Consejo, al Comité Económico y Social Europeo y al Comité de las Regiones: Un marco estratégico en materia de clima y energía para el periodo de 2020 a 2030. Bruselas, 22 de enero de 2014, SWD(2014) 16 final.

FERNÁNDEZ EGEA, R.M., "El deber de protección frente a los efectos del cambio climático, a propósito de la sentencia del Tribunal de La Haya (Rechtbank Den Haag) de 24 de junio de 2015”, Aquiescencia: blog de derecho internacional de Carlos Espósito, 21 de julio de 2015. Disponible en: https://aquiescencia.net/2015/07/21/el-deber-deproteccion-frente-a-los-efectos-del-cambio-climatico-por-rosa-fernandez-egea/

Urgenda Foundation. Statement of reply. 21 de mayo de 2015. Párr. 315. Disponible en: http://www.urgenda.nl/en/climate-case/

Urgenda Foundation. Summons. 25 de junio de 2014. Disponible en: http://www.urgenda.nl/en/climate-case/ 